\title{
A Note on Reporting P-Value in Medical Research
}

\section{Marimuthu $\mathbf{P}^{*}$}

Department of Statistics, National Institute of Health and Family Welfare, New Delhi, India

*Corresponding author: Marimuthu P, Department of Statistics, National Institute of Health and Family Welfare, India, Tel: +91-080-26995115; E-mail: p_marimuthu@hotmail.com

Received date: October 31, 2016; Accepted date: December 15, 2016; Published date: December 20, 2016

Copyright: @ 2016 Marimuthu P. This is an open-access article distributed under the terms of the Creative Commons Attribution License, which permits unrestricted use, distribution, and reproduction in any medium, provided the original author and source are credited.

Citation: Marimuthu P (2016) A Note on Reporting P-Value in Medical Research. J Biom Biostat 7: 328. doi:10.4172/2155-6180.1000328

\section{Case Report on P-Value in Medical Research}

For rejecting the Null Hypothesis H0, the level of Significance $\mathrm{P}<0.05$ is uniformly accepted as the threshold value in medical science research. After 90 s by implication of computers and software in statistical analysis the reporting style of $\mathrm{P}$ value is changed in all the journals.

If a $\mathrm{P}$ value $2.876^{\star} \mathrm{E}-13$, reporting this figure without any roundingoff may not be appreciated, [1] by all the Medical researchers. Some software shows the $\mathrm{P}$ value as 0.000 (If you click [2] it will show the original $\mathrm{P}$ value) and there is no standard format for reporting the $\mathrm{P}$ value as the level of significance. There is lot of discussions $[3,4]$ on how to report $\mathrm{P}$ value. If this $\mathrm{P}$ value, reported as $2.876^{\star} \mathrm{E}-13$ (not a simple format) or 0.000 is debated, and some statistician are in the opinion that instead of writing $\mathrm{P}$ as 0.000 it should be shown [5] as $\mathrm{P}<0.001$ (but strictly speaking $\mathrm{P}<0.0000000000002875$ ). Assuming that most of the journals allow $\mathrm{P}$ value for three decimals, now the big question is $\mathrm{P}=0.000$ or $\mathrm{P}<.001$ when the original value is 0.0000000000002876 .

It is rational to consider that $\mathrm{P}$ can be reported as $\mathrm{P}=0.000$ with logic that the difference between any two equal valued integers are written as simply zero/the difference between 1.897432 and 1.897432 is too written as zero and not as 0.000000 . From the following table some phrases have special meaning in statistics.

Terms

Error

$\mathrm{r}=0.587$ and $\mathrm{r}=-0.886$

Bias

In general

Mistake

0.587 is greater

Prejudice or unfair
Statistical Meaning

Residual SS or O-E value

-0.886 is greater

Difference between Parameter and the Estimate (Many type of Bias)

And so on.

\section{Conclusion}

Hence by induction, it is proposed that $\mathrm{P}$ can be reported as 0.000 with the statistical meaning that the 'probability values is zero at least for first three decimals, and not to consider this 0.000 as just mathematical zero.

Terms

$\mathrm{P}=0.000$

In general

0 (Zero)

Statistical Meaning

Probability values is zero at least for first three decimals,

Unless a special situation warranted and if data is analysed using computer then $\mathrm{P}$ can be reported for three decimals with equal sign.

\section{References}

1. Panagiotakos DB (2008) The Value of P-Value in Biomedical Research. Open Cardiovasc Med J 2: 97-99.

2. http://stats.stackexchange.com/questions/15228/controlling-p-value-inspss

3. http://www.editage.com/insights/the-correct-way-to-report-p-values

4. http://www.pmean.com/12/zero.html

5. https://disqus.com/home/discussion/insightsenglish/ the_correct_way_to_report_p_values/ 